\title{
Performance Appraisal for Green/Environmental Friendliness of a Supply Chain Department
}

\author{
Solomon Olasunkanmi Odeyale \\ Sunderland Business School, University of Sunderland (United Kingdom) \\ solomon.odeyale@gmail.com
}

Received: December 2013

Accepted: July 2014

\section{Abstract:}

Purpose: This paper aims at proposing a method for evaluating the environmental friendliness of a supply chain department in any organization. Supply chain involves activities that could affect the natural environment and if these activities are not properly evaluated and monitored, it could affect the natural environment and also generate ecological performance change.

Design/methodology: The model for the appraisal consists of 5 criteria and 30 subcriteria. The method is applied at 3 levels; beginning with finding the relative weight of the subcriteria under each criterion using Analytic Hierarchy Process (AHP), followed by computing the value associated with each level descriptor in a scale. Some subcriteria have 5 level descriptors (very strong/moderate /weak/very weak / no), some subcriteria have 3 level descriptors (always / sometimes/ never) and some have 2 levels descriptor (yes/no). Finally, the method is concluded by the means of an additive model, whereby the weight associated with each subcriteria is multiplied by the corresponding level descriptor and summed up to get the limit/state. This methodology is called the weighing multiplication and additive model (WMAAM).

Findings: Supply chain (SC) involves operational activities and for these activities to be environmental friendly, they have been categorized under criteria namely; green design, green procurement, green manufacturing, environmental management and green marketing. These criteria which consist of 30 subcriteria are evaluated in other to compute the overall environmental friendly appraisal of the SC department. 
Practical implications: The study plays important role in understanding various areas to be monitored and considered during supply chain activities in order to achieve a green supply chain management or an environmental friendly supply chain.

Originality/value: The main contribution of this work is to propose an effective methodology that guides SC practitioners on carrying out green performance appraisal of a SC department in any organization.

Keywords: Analytic hierarchy process (AHP), environmental management, green supply chain management, performance appraisal

\section{Introduction}

Although the supply chain function of any organization is an important element of modern business, one must also consider the implication of these activities to the environment we live in. Supply chain management involves various activities starting from procurement of raw materials, design of products, manufacturing of products, marketing of products, down to the logistics involved in getting the product to the consumer. Each of these activities, if not operated from the perspective of environmental sustainability, could cause threat to the ecosystem. For example, a company that involves in the creation of manufactured products that uses processes that are polluting and do not conserve energy or natural resources, poses threat to the environment. On the other hand, a company that involves in the creation of manufactured products using processes that are non-polluting, conserve energy and natural resources are economically sound and safe for the environment and consumers. This process is called green manufacturing. Other environmental friendly supply chain processes are green procurement, green design, environmental management and green marketing. (Odeyale, Alamu \& Odeyale, 2013).

Supply chain involves activities that could affect the natural environment and also generate environmental performance change. This is why there is a need to audit supply chain department based on environmental sustainability. Every organization should know their current status and aim at developing or improving its sustainable and environmental friendly supply chain operations. Green or environmental friendly supply chain generally refers to supplier product and environmentally related management, or to incorporating environmental protection principles into supplier management systems, the purpose of which is to enhance market competence by implanting more environmental protection concepts (Lin \& Juang, 2008).

This study proposes an appraisal to detect/monitor the state of green operation of any supply chain department. The improvement developed can be quantitatively measured and translated into a qualitative value that provides a general state of the environmental friendliness of the 
supply chain department. In this paper, an environmental friendliness appraisal has been developed using an additive multicriteria methodology. The appraisal has been able to identify the current state of a supply chain department and compare this state with the highest and lowest possible state.

\section{Literature review}

The appraisal process starts with the identification of the set of criteria to be used for evaluation. The criteria are listed as follows;

The decision criteria used for the evaluation of green supply chain management based on different sections of industrial operation are listed below and briefly explained (Odeyale et al., 2013).

- Green Design (GD): This is also known as sustainable design or environmental design. It involves the designing of physical objects, services, and the built environment to conform to the principles of social, economic and ecological sustainability. It aims at eliminating negative environmental impact completely, through green skillful and sensitive design. Green design requires; no non-renewable resources, impacts the environment minimally, and connect consumers with the natural environment. The concept of green design involves; abstaining from the use of toxic substance, energy savings, complying with design for disassembly, reuse and recycling (DfDRR) and increasing innovation capabilities.

- Green Procurement (GP): Green procurement or sustainable procurement involves considering environmental aspects, potential impacts and costs, associated with the life-cycle assessment of goods and services being purchased. It involves the practice of procuring products and services that are less harmful to the environment. Products acquired should be those that are made with less harmful materials or which when produced or used or consumed would have minimal impacts on the environment. This concept involves green logistics, green competencies, green image and green management abilities.

- Green Manufacturing (GM): Green manufacturing involves the creation of manufactured products through processes that are non-polluting, conserves energy and natural resources and are economically sound and safe for the environment and consumers. The concept of green manufacturing involves re-manufacturing, use of environmental friendly materials, recycling, pollution reduction capabilities etc.

- Environmental Management (EM): This involves the management of all components of the bio-physical environment, both living (biotic) and non-living (abiotic). The main role of environmental management is to manage the productive use of natural resources without reducing their efficiency and quality. Environmental management is a practice 
by which environmental resources and its impact are regulated. Environmental management involves use of natural raw materials, emission control, resource recovery and recycle of waste.

- Green Marketing (GMt): This is the marketing of products that are presumed to be environmentally safe. It involves incorporating a broad range of activities which includes product modification, amendments to the production process, packaging changes, as well as modifying advertising. The concept of green marketing includes making good use of ICT tools, disclosure of environmental information of products and services, green market share, stakeholders' relationship, green packaging, green advertisement etc.

To obtain the information from the company under study, a questionnaire was prepared. This questionnaire is a general questionnaire and can therefore be applied to any company or enterprise. Each criterion includes different subcriteria; each subcriterion has a descriptor associated and constructed with the levels that describe plausible impacts of the alternatives with respect to each subcriterion. The subcriteria included inside the criterion Green manufacturing are presented below;

- What is the degree of green energy utilization?

- What is the reuse time of hazardous waste?

- Is there a provision for re-manufacturing process?

- What quantities of environmental friendly material / resources are used?

- Are there provisions for recycling operations?

- Does the management embark on pollution reduction capabilities?

- What is the total amount of energy or / and resource utilization?

- How can you quantify the amount of hazardous waste during and after manufacturing process?

The subcriteria included inside the criterion environmental management are presented below:

- How would you rate your emission control level?

- What level of natural raw materials are used?

- How are unwanted waste disposal operations?

- Are training courses provided and/or updating of technical knowledge on environmental sustainability?

- How often does the management carry out environmental impact assessment?

- Are the products of this company biodegradable? 
Based on the literature review of green supply chain management, there have been several researches which involve green, environmental or sustainable concepts to traditional supply chain management. Few works on evaluation of supply chain management are highlighted as follows; Webb (1994) emphasized that product manufacturing had to use environmental criteria to select appropriate raw materials while also paying attention to recycling and the green purchasing concept as well. Beamon (1999) proposed that environmental factor must be introduced to the supply chain model to put forward wider supply chain design methods. Kuo et al. (2004) pointed out that, in the entire process of supply chain management, the combination of the process; the products, the packaging, and the distribution have to take environmental problems into account, not only by reducing the social burden on the environment, but also by meeting environmental laws, and lowering green trading barriers. Lai (2004) suggested that building green supply chains has become a major challenge, but that the trend of providing green products can allow us to advance towards a sustainable society. Lin and Juang (2008) used AHP methodology to select green suppliers for a biotechnology industry. Ali and Kannan (2010) developed a model of the drivers affecting the implementation of green supply chain management using an Interpretive Structural Modeling (ISM) framework. The various drivers of green supply chain management (GSCM) were identified based on the GSM literature and on consultations with experts in the industry. The model developed was validated on a case study involving a manufacturing firm in southern India. Ru-Jen, Rong-Huei and Thi-Hang (2011) explored the criteria that influence the performance of the automobile manufacturing industry, using the fuzzy set theory and Decision Making Trial and Evaluation Laboratory. The method was used to evaluate its performance and find key criteria in improving the manufacturers' green performance. Kuo-Jui, Ming-Lang and Truong (2011) used the fuzzy Decision Making Trial and Evaluation Laboratory (DEMATEL) method to find influential factors in selecting GSCM criteria. They evaluated suppliers' performance to find key factor criteria to improve performance and provide a novel approach of decision-making information in GSCM implementation. Chan, He, Chan and Wang (2012) proposed and empirically tested a model delineating the relationship among environmental orientation, green supply chain management (GSCM) activities (green purchase, customer cooperation and investment recovery) and corporate performance. Chiau-Ching, Hsu-Shih, Huan-Jyh and Kun-Shan (2012) designated green supply chain management (GSCM) strategies to effectively direct business functions and activities in a leading Taiwanese electronics industry. Yao-Fen, Su-Ping, Yi-Ching and Chen-Tsang (2013) established a green management standard with GrSCM that green restaurants can implement. They combined GrSCM for food and beverage management to develop green restaurant standards, and primarily adopted the Delphi Technique to develop green standards of restaurant management. Payman and Cory (2013) identified and analyzed the published definitions of green supply chain management (GSCM) and sustainable supply chain management (SSCM) and later proposed a new definition for SSCM. Ming-Lang, Ru-Jen, Yuan-Hsu, Rong-Hui and Kimhua (2013) explored the differences between close-loop and open hierarchical structures, which are used in the analytical network process (ANP) analysis of 
green supply chain management (GSCM) under uncertainty. They examined the interdependence among the proposed aspects and criteria used to assess GSCM in two hierarchical structures and compared the results to those of a real situation. Odeyale et al. (2013) proposed a Fuzzy-AHP model for the evaluation and selection of an effective green supply chain management strategy.

\section{Methodology}

The green appraisal or performance appraisal of the environmental friendliness is developed by the means of an additive model known as weighing multiplication and additive model (WMAAM). Scores are multiplied by weights and the products summed. The formula is represented in equation 1 below; Let vij represent the value associated with the value of option $i$ on criterion $j$. Let wj represent the weight assigned to criterion $j$. Then, the overall value of option $i$ is simply;

$$
\begin{gathered}
V_{i}=\sum_{j} w_{j} v_{i j} \\
V_{i}=\sum v_{i}
\end{gathered}
$$

In words, the scores assigned to the states of an option on all the criteria is derived by multiplying the respective weights assigned to the subcriteria and the value of the corresponding level descriptor, and those products summed across all the criteria. This methodology allows a hierarchical representation of objectives and criteria by clustering them under 'parent' nodes (Carnero, 2008).

\subsection{Weighing process}

\section{Step 1. Finding the weights of subcriteria using AHP}

Converting decision criteria into numerical values could be very intricate, however the decision maker should be able to categories each criteria according to their importance. This can be done by a process called method called Analytical Hierarchy Process. AHP is a multi-criteria decision-making method developed by Saaty (Saaty T. and Vargas L., 1982). AHP aims at quantifying relative weights for a given set of criteria on a ratio scale. Two features of AHP differentiate it from other decision-making approaches. One, it provides a comprehensive structure to combine the intuitive rational and irrational values during the decision making process. The other is its ability to judge the consistency in the decision-making process. To make a decision in an organised way to generate priorities we need to decompose the decision into the following steps. 
1) Define the problem and determine the kind of knowledge sought.

2) Structure the decision hierarchy from the top with the goal of the decision, then the objectives from a broad perspective, through the intermediate levels (criteria on which subsequent elements depend) to the lowest level (which usually is a set of the alternatives).

3) Construct a set of pairwise comparison matrices. Each element in an upper level is used to compare the elements in the level immediately below with respect to it.

4) Use the priorities obtained from the comparisons to weigh the priorities in the level immediately below. Do this for every element. Then for each element in the level below add its weighed values and obtain its overall or global priority.

One of the most crucial steps in many decision-making methods is the accurate estimation of the pertinent data. This is a problem not bound in the AHP method only, but it is crucial in many other methods which need to elicit qualitative information from the decision-maker. Very often qualitative data cannot be known in terms of absolute values. For instance," what is the worth of specific computer software in terms of a user adaptivity criterion?" Although information about questions like the previous one are vital in making the correct decision, it is very difficult, if not impossible, to quantify them correctly. Therefore, many decision-making methods attempt to determine the relative importance, or weight, of the alternatives in terms of each criterion involved in a given decision-making problem. An approach based on pairwise comparisons which was proposed by Saaty has long attracted the interest of many researchers. Pairwise comparisons are used to determine the relative importance of each alternative in terms of each criterion. In this approach the decision-maker has to express his opinion about the value of one single pairwise comparison at a time. Usually, the decisionmaker has to choose his answer among 10-17 discrete choices. Each choice is a linguistic phrase. Some examples of such linguistic phrases are: "A is more important than B", or "A is of the same importance as B", or "A is a little more important than B", and so on (Table 1 ).

\begin{tabular}{|c|c|c|}
\hline $\begin{array}{l}\text { Intensity of } \\
\text { Importance }\end{array}$ & Definition & Explanation \\
\hline 1 & Equal importance & Two activities contribute equally to the objective \\
\hline 3 & Weak importance of one over another & $\begin{array}{c}\text { Experience and judgment slightly favour one activity } \\
\text { over another }\end{array}$ \\
\hline 5 & Essential or strong importance & $\begin{array}{c}\text { Experience and judgment strongly favour one activity } \\
\text { over another }\end{array}$ \\
\hline 7 & Demonstrated importance & $\begin{array}{c}\text { An activity is strongly favoured and its dominance } \\
\text { demonstrated in practice }\end{array}$ \\
\hline 9 & Absolute importance & $\begin{array}{l}\text { The evidence favouring one activity over another is } \\
\text { of the highest possible order of affirmation }\end{array}$ \\
\hline $2,4,6,8$ & $\begin{array}{c}\text { Intermediate values between the two } \\
\text { adjacent judgments }\end{array}$ & When compromise is needed \\
\hline $\begin{array}{c}\text { Reciprocals of } \\
\text { above } \\
\text { nonzero }\end{array}$ & $\begin{array}{l}\text { If activity has one of the above nonzero } \\
\text { numbers assigned to it when compared } \\
\text { with activity } j \text {, then } j \text { has the reciprocal } \\
\text { value when compared with I. }\end{array}$ & \\
\hline
\end{tabular}

Table 1. Scale of Relative Importance (Saaty, 1980) 
Pairwise comparisons are quantified by using a scale. Such a scale is a one-to-one mapping between the set of discrete linguistic choices available to the decision maker and a discrete set of numbers which represent the importance, or weight, of the previous linguistic choices. The scale proposed by Saaty is depicted in Table 1. In Saaty's scale, 9 is established as the upper limit, 1 as the lower limit and a unit difference between successive scales values. The values of the pairwise comparisons in the AHP are determined according to the scale introduced by Saaty (1980). According to this scale, the available values for the pairwise comparisons are members of the set: $\{9,8,7,6,5,4,3,2,1,1 / 2,1 / 3,1 / 4,1 / 5,1 / 6,1 / 7,1 / 8,1 / 9\}$ (see also Table 1).

The criteria and subcriteria are organized in a tree structure as shown in Figure 1 . The weighing process of the subcriteria is computed by hierarchical ranking carried out by application of AHP. For example under the criterion green design, there are four subcriteria namely; Energy savings (GD1), increasing innovation capabilities (GD2), complying with the Dfddr principles (GD3) and abstaining from utilizing toxic substances (GD4). These subcriteria are ranked in such a way that the highest ranking has the highest relevancy to attain the criterion goal by pairwise comparison (Table 1 ).

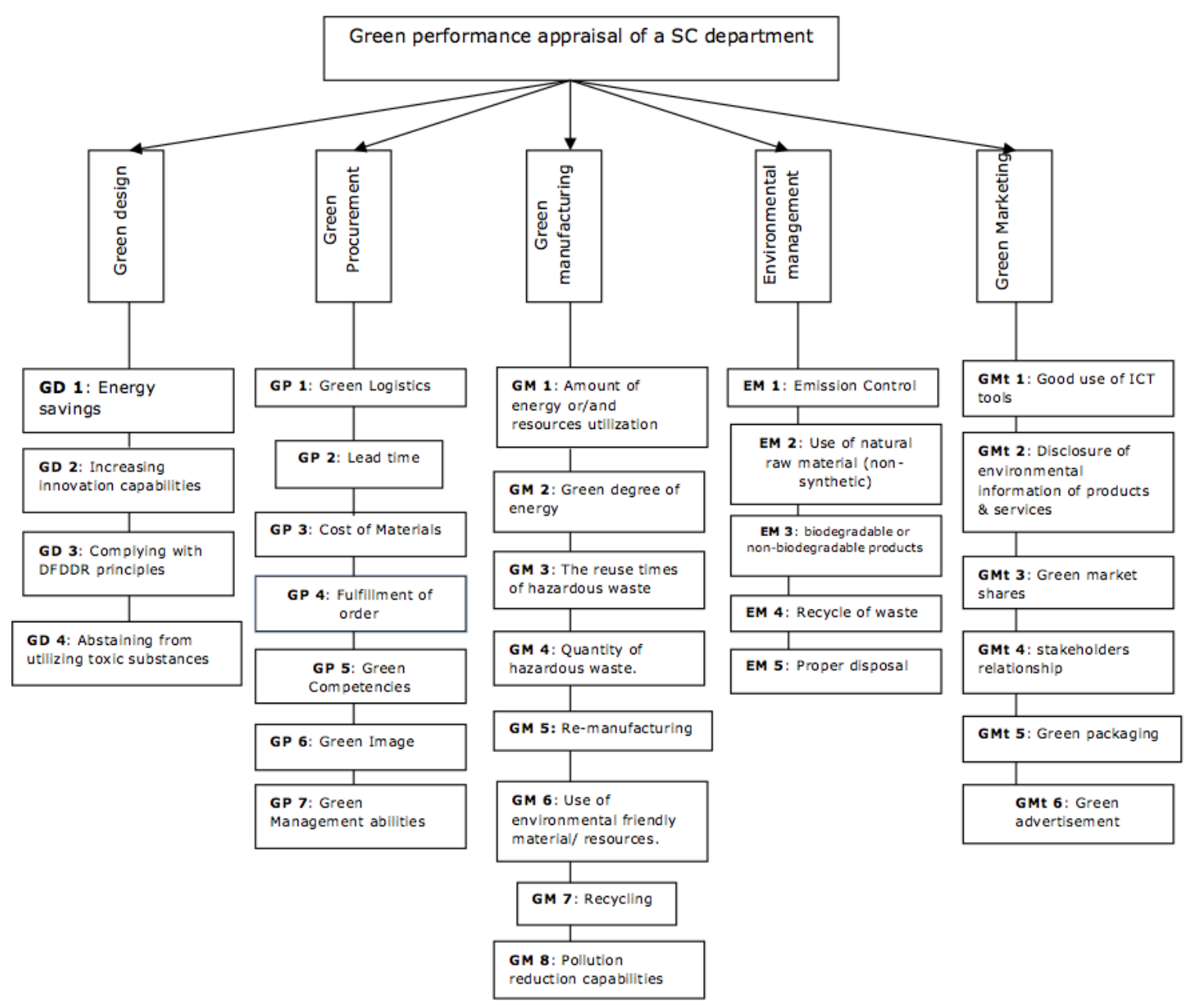

Figure 1. The hierarchical and appraisal tree 


\section{Step 2. Computing the value of the level descriptor of subcriteria}

The green appraisal is composed of 5 criteria and 30 subcriteria have shown in Figure 1 . The level descriptor is basically the corresponding value associated with the response to each subcriterion. As explained earlier in the introduction, each criterion includes different subcriteria; each subcriterion has a descriptor associated and constructed with the levels that describe plausible impacts of the alternatives with respect to each subcriterion. The subcriteria included inside the criterion Green manufacturing are presented below;

- What is the degree of green energy utilization?

- What is the reuse time of hazardous waste?

- Is there a provision for re-manufacturing process?

- What quantities of environmental friendly material / resources are used?

- Are there provisions for recycling operations?

- Does the management embark on pollution reduction capabilities?

- What is the total amount of energy or / and resource utilization?

- How can you quantify the amount of hazardous waste during and after manufacturing process?

The degree of the answers to these questions is what is referred to as level descriptor. The subcriteria have questions embedded in them in which their responses to the questions are in 5,3 or 2 levels. There are some subcriteria with only two levels in the scale i.e. $L 1_{100 \%}$ and $L 2_{0 \%}$ (answers to yes/no questions) as shown in Figure 2, while some subcriteria have three levels in the scale i.e. $\mathrm{L} 1_{100 \%}, \mathrm{~L} 2_{50 \%}$ and $\mathrm{L} 3_{0 \%}$, (answers to always/sometimes/never questions) as shown in Figure 3 and some subcriteria with the five level scale i.e. $L 1_{100 \%,} L 22_{75 \%}, L 3_{50 \%}, L 4_{25 \%}$ and $\mathrm{L} 5_{0 \%}$ (answers to very strong/strong/moderate/weak/no). For example there are four subcriteria under the criterion green design namely; Energy savings (GD1), increasing innovation capabilities (GD2), complying with the Dfddr principles (GD3) and abstaining from utilizing toxic substances (GD4); have questions in the questionnaire such as; how often do you engage in energy savings during product design?, Rate your organizations based on complying with the disassembly, reuse and recycling (DfDRR) principles?, How often does your organization use toxic substances during product design? and so on. The response to these questions could be sometimes, never, strong, weak, yes, no etc. whatever the response is, the associated value is the level descriptor. Note that under criterion green manufacturing, evaluating response from the questionnaire on questions such as What is the reuse time of hazardous waste?, How can you quantify the amount of hazardous waste during and after manufacturing process? and so on, gives higher level descriptor when the numbers are lower and lower level descriptor when the numbers are higher. This is due to the facts that an organization that has a smaller number of reuse times of hazardous waste or amount of 
hazardous waste during and after manufacturing process is more environmental friendly while organizations that have higher number are less environmental friendly.

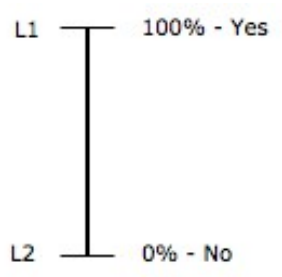

Figure 2. Level descriptor of a subcriterion with two levels

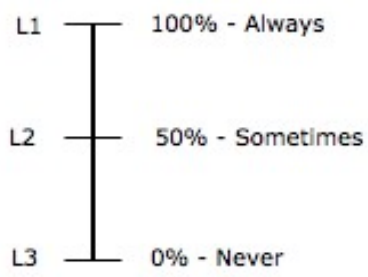

Figure 3. Level descriptor corresponding to the subcriterion with three levels descriptor

\section{Step 3. Computing the score of the state}

The score of the state is computed by multiplying the weight of the subcriteria with its corresponding level descriptor. The flowchart for all the 3 steps is illustrated in Figure 4 below.

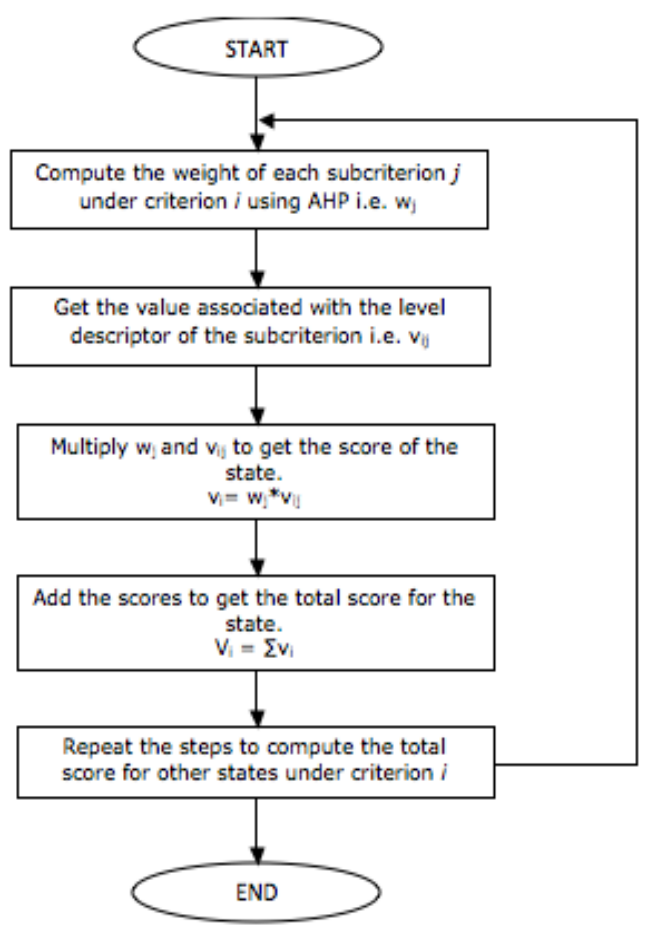

Figure 4. Flowchart showing the steps involved in the performance appraisal process 


\section{States}

The alternative states considered in this paper are excellent state, excellent / satisfactory state limit, satisfactory/acceptable limit, acceptable / alert limit, alert / catastrophic limit and totally catastrophic state. This model was used to evaluate the present state of the environmental friendliness of the supply chain department of an organization, and the alternative state is called current state/status using Equation 1.

\section{Limits between states}

The limit between each state values were obtained by analyzing the level in which each subcriterion should be considered, once that criterion is in a specific state. For example, under the green manufacturing criterion:

a) The excellent state is obtained with all the subcriteria at the best level i.e. L1 $(100 \%)$

b) The excellent / satisfactory limit is obtained when subcriteria GM1, GM2, GM6 and GM 8 are at the second best level i.e. L2 (75\%) and the subcriteria GM3, GM4, GM5 and GM7 are at the best level.

c) The satisfactory / acceptable limit is computed by considering the subcriteria GM1, GM2, GM4 at second best level, GM5, GM7 at best level and the subcriteria GM3, GM6, GM8 at the third best level L3 (50\%).

d) The acceptable/alert limit corresponds with the subcriterion GM4 at the second best level, GM1, GM2, GM3, GM6, GM8 at the third best level and GM5, GM7 are the fourth best level.

e) The alert / catastrophic limit is evaluated with the subcriteria GM3 at the third best level and the rest subcriteria at the fourth best level.

f) The totally catastrophic limit is computed with all subcriteria at the worth level. L5 (0\%)

\begin{tabular}{|c|c|c|c|c|c|c|}
\hline Subcriteria (weight) & a & b & c & d & e & $f$ \\
\hline GM1 (10.96) & $\mathrm{L}_{100 \%}$ & $\mathrm{~L} 2{ }_{75 \%}$ & $\mathrm{~L} 2{ }_{75 \%}$ & L3 $3_{50 \%}$ & $L^{L}{ }_{25 \%}$ & $\mathrm{~L}_{0 \%}$ \\
\hline GM2 (12.49) & $\mathrm{L}_{100 \%}$ & $\mathrm{~L} 2{ }_{75 \%}$ & $\mathrm{~L} 2{ }_{75 \%}$ & $L 3_{50 \%}$ & $\mathrm{~L}_{25 \%}$ & $\mathrm{~L}_{0 \%}$ \\
\hline GM3 (15.48) & $\mathrm{L}_{100 \%}$ & $\mathrm{~L}_{100 \%}$ & $\mathrm{~L} 2_{50 \%}$ & $L 2_{50 \%}$ & $L 2_{50 \%}$ & $\mathrm{~L}_{0 \%}$ \\
\hline GM4 (15.48) & $\mathrm{L}_{100 \%}$ & $\mathrm{~L}_{100 \%}$ & $\mathrm{~L} 2_{75 \%}$ & $L 2_{75 \%}$ & $L 4_{25 \%}$ & $\mathrm{~L}_{0 \%}$ \\
\hline GM5 $(9.23)$ & $\mathrm{L1}_{100 \%}$ & $\mathrm{~L}_{100 \%}$ & $\mathrm{~L}_{100 \%}$ & & & $\mathrm{~L} 2_{0 \%}$ \\
\hline GM6 (13.15) & $\mathrm{L}_{100 \%}$ & $\mathrm{~L} 22_{75 \%}$ & $\mathrm{~L}_{50 \%}$ & $\mathrm{~L}_{50 \%}$ & $L 4_{25 \%}$ & $\mathrm{L5}_{0 \%}$ \\
\hline GM7 (9.13) & $\mathrm{L}_{100 \%}$ & $\mathrm{~L}_{1} 100 \%$ & $\mathrm{~L}_{1} 100 \%$ & & & $\mathrm{~L} 2{ }_{0} \%$ \\
\hline GM8 (14.07) & $\mathrm{L}_{100 \%}$ & $\mathrm{~L} 2_{50 \%}$ & $\mathrm{~L}_{50 \%}$ & $\mathrm{~L}_{50 \%}$ & & $\mathrm{~L}_{0 \%}$ \\
\hline & 100 & 83 & 69 & 45 & 21 & 0 \\
\hline
\end{tabular}

Table 1. Limits between state for green manufacturing criterion 
As seen in Table 1 above, the score for each state was computed by multiplying the value of the level descriptor by the corresponding weight of the subcriterion, and summing it up;

$$
\begin{aligned}
& c(\text { acceptable state })=[(0.75 \times 10.96)+(0.75 \times 12.49)+(0.50 \times 15.48)+ \\
& (0.75 \times 15.48)+(1 \times 9.23)+(0.5 \times 13.15)+(1 \times 9.13)+(0.5 \times 14.07)]=69
\end{aligned}
$$

Similar procedures as stated above were applied to all the criteria to set limits between states, for example under criterion Green design which has 4 subcriteria;

a) The excellent state is obtained with all the subcriteria at the best level i.e. L1 $(100 \%)$

b) The excellent / satisfactory limit is obtained when subcriteria GD2 and GD3 are at the second best level i.e. L2 (75\%) and the subcriteria GD1 and GD4 are at the best level.

c) The satisfactory / acceptable limit is computed by considering the subcriteria GD3 and GD4 at second best level, GD1 at best level and the subcriteria GD2 at the third best level L3 (50\%).

d) The acceptable/alert limit corresponds with the subcriterion GD3 and GD4 at the second best level, GD1 at the third best level and GD 2are the fourth best level.

e) The alert / catastrophic limit is evaluated with the subcriteria at the fourth best level.

f) The totally catastrophic limit is computed with all subcriteria at the worth level. L5 (0\%)

\begin{tabular}{|c|c|c|c|c|c|c|}
\hline Subcriteria (weight) & a & b & c & d & e & f \\
\hline GD1 (32.41) & $\mathrm{L} 1_{100}$ & $\mathrm{~L} 1_{100}$ & $\mathrm{~L} 1_{100}$ & $\mathrm{~L} 2_{50 \%}$ & $\mathrm{~L}_{0 \%}$ & $\mathrm{~L} 3_{0 \%}$ \\
\hline GD2 (13.57) & $\mathrm{L} 1_{100}$ & $\mathrm{~L} 2_{75}$ & $\mathrm{~L} 3_{50}$ & $\mathrm{~L} 4_{25}$ & $\mathrm{~L} 3_{50 \%}$ & $\mathrm{~L} 5_{0 \%}$ \\
\hline GD3 (17.96) & $\mathrm{L} 1_{100}$ & $\mathrm{~L} 2_{50}$ & $\mathrm{~L} 2_{50}$ & $\mathrm{~L} 2_{50 \%}$ & $\mathrm{~L} 2_{50 \%}$ & $\mathrm{~L} 3_{0 \%}$ \\
\hline GD4 (36.06) & $\mathrm{L} 1_{100}$ & $\mathrm{~L} 1_{100}$ & $\mathrm{~L} 2_{50}$ & $\mathrm{~L} 2_{50 \%}$ & $\mathrm{~L} 2_{50 \%}$ & $\mathrm{~L} 3_{0 \%}$ \\
\hline & 100 & 88 & 66 & 46 & 33 & 0 \\
\hline
\end{tabular}

Table 2. Limits between state for green design criterion

Hence, the limits between states for all the criteria are presented in Table 3-7 below. To obtain the limit between states for global audit as shown in Table 8, the mean/average limit of each state were computed. For the performance appraisal of any organization, in our case a supply chain department, a level of descriptor should be associated with each subcriterion. As explained earlier, there are some subcriteria with only two levels in the scale i.e. $L 1_{100 \%}$ and L2 $2_{0 \%}$ (results of yes/no questions), while some subcriteria have three levels in the scale i.e. $\mathrm{L} 1_{100 \%}, \mathrm{~L} 2_{50 \%}$ and $\mathrm{L} 3_{0 \%}$ (answers to always/sometimes/never questions) and some subcriteria with the five level scale. 


\begin{tabular}{|c|c|}
\hline Limits & Value \\
\hline Excellent & $88 \%-100 \%$ \\
\hline Satisfactory & $66 \%-87 \%$ \\
\hline Acceptable & $46 \%-65 \%$ \\
\hline Alert & $33 \%-45 \%$ \\
\hline Catastrophic & $0 \%-32 \%$ \\
\hline
\end{tabular}

Table 3. Limit values between states in green design criterion

\begin{tabular}{|c|c|}
\hline Limits & Value \\
\hline Excellent & $86 \%-100 \%$ \\
\hline Satisfactory & $71 \%-85 \%$ \\
\hline Acceptable & $44 \%-70 \%$ \\
\hline Alert & $33 \%-43 \%$ \\
\hline Catastrophic & $0 \%-32 \%$ \\
\hline
\end{tabular}

Table 4. Limit values between states in green procurement criterion

\begin{tabular}{|c|c|}
\hline Limits & Value \\
\hline Excellent & $83 \%-100 \%$ \\
\hline Satisfactory & $69 \%-82 \%$ \\
\hline Acceptable & $45 \%-68 \%$ \\
\hline Alert & $21 \%-44 \%$ \\
\hline Catastrophic & $0 \%-20 \%$ \\
\hline
\end{tabular}

Table 5. Limit values between states in green manufacturing criterion

\begin{tabular}{|c|c|}
\hline Limits & Value \\
\hline Excellent & $79 \%-100 \%$ \\
\hline Satisfactory & $66 \%-78 \%$ \\
\hline Acceptable & $52 \%-65 \%$ \\
\hline Alert & $31 \%-51 \%$ \\
\hline Catastrophic & $0 \%-30 \%$ \\
\hline
\end{tabular}

Table 6. Limit values between states in environmental management criterion

\begin{tabular}{|c|c|}
\hline Limits & Value \\
\hline Excellent & $73 \%-100 \%$ \\
\hline Satisfactory & $63 \%-72 \%$ \\
\hline Acceptable & $27 \%-62 \%$ \\
\hline Alert & $17 \%-26 \%$ \\
\hline Catastrophic & $0 \%-16 \%$ \\
\hline
\end{tabular}

Table 7. Limit values between states in green marketing criterion

\begin{tabular}{|l|c|}
\hline \multicolumn{1}{|c|}{ Alternatives } & Limits between states \\
\hline Excellent State & $82 \%-100 \%$ \\
\hline Satisfactory State & $67 \%-81 \%$ \\
\hline Acceptable State & $43 \%-66 \%$ \\
\hline Alert State & $26 \%-42 \%$ \\
\hline Catastrophic State & $<26 \%$ \\
\hline
\end{tabular}

Table 8. Limit values between states considering the global audit 


\section{Results}

The questionnaire with the information about the current state of the supply chain department was completed by an independent person to the organization. Thus, from the previous semantic values stated in the methodology above, the current state of the supply chain department is computed to be 71.7 (Satisfactory / Acceptable limit) on the $0-100$ scale as shown in Table 8. In the area of green design, the department scored 71.9 (Acceptable), under the criterion green procurement it scored 81.3 (Satisfactory). Other appraisals are; green manufacturing, environmental management and green marketing are 61.9 (Acceptable), 67 (Acceptable) and 76.4 (Excellent) respectively. From the performance appraisal, it is seen that the organization had the lowest score under green manufacturing. This is majorly due to the fact that the organization does not have provision for recycling processes as shown in Figure 8. There is also need to improve on some subcriteria (such as pollution reduction capabilities, recycling, and hazardous waste management) under this criterion. The organization scored low under these subcriteria which in turn affected the overall score of the green manufacturing criterion.

The graphical representation of the current state based each criterion is shown in Figure 5 (to prevent ambiguity only green design criterion is shown) and the overall status is also computed by calculating the average score of the appraisal on the criteria (Figure 6).

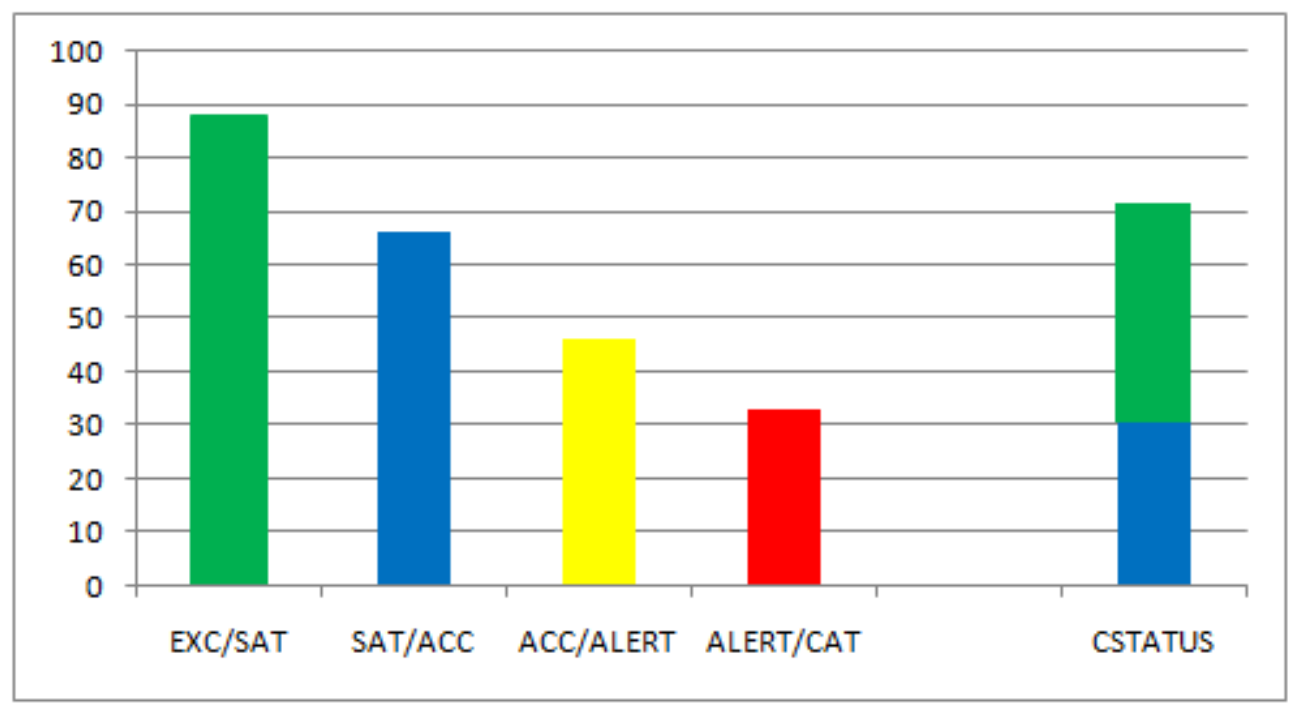

Figure 5. Current status of the department under the green design criterion 


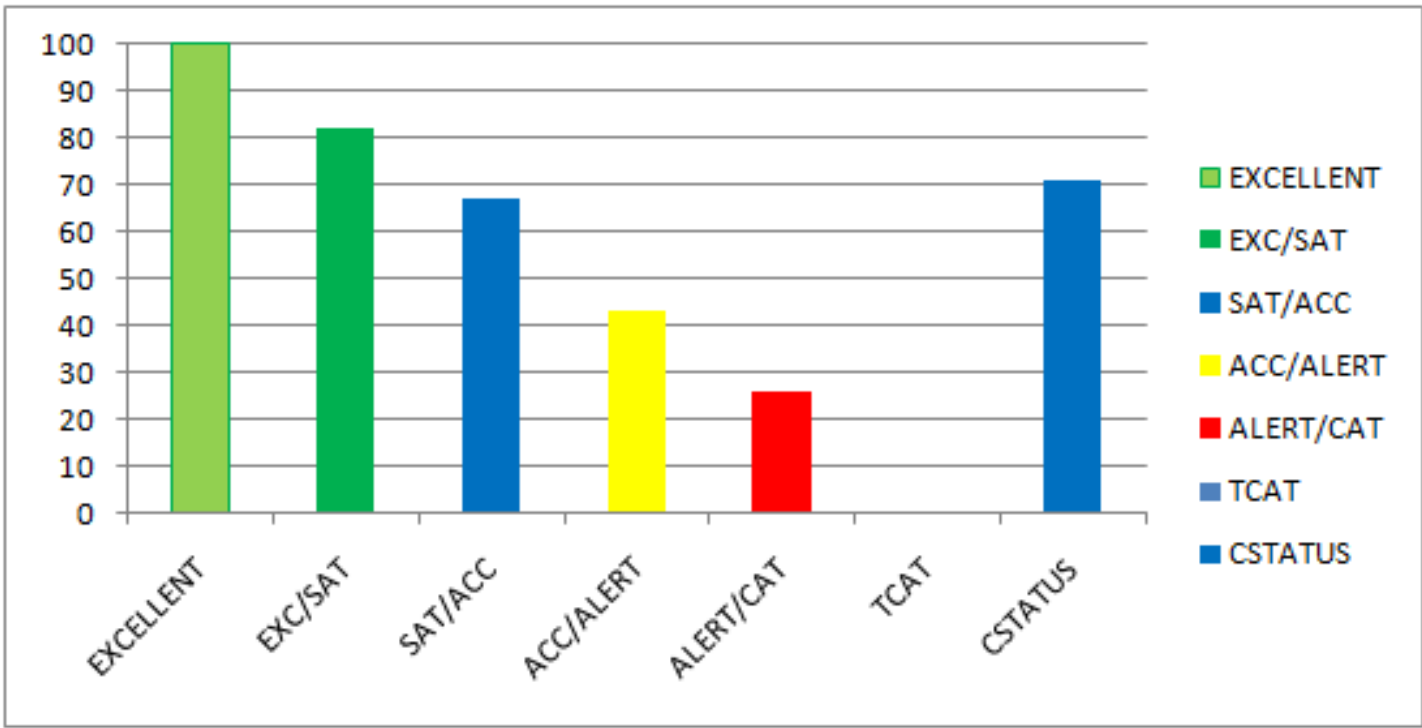

Figure 6. Overall current status of the department

\section{Concluding remark}

A WMAAM multicriteria technique has been used to perform a green appraisal of a supply chain department. The appraisal is objective and can be distinguished for any organization by the means of establishing the specified limits between weights and state. This performance appraisal can be used from time to time to evaluate the current environmental friendly status of the SC department. It is essential to monitor the status of the SC department. The objective of this study is to create a model for evaluation of a supply chain department from the perspective of environmental friendliness. Key criteria of green supply chain management were used for the appraisal. Being green and ethical is no longer an option; it is a necessity in supply chain management. As mentioned earlier, supply chain involves activities that could affect the natural environment and also generate environmental performance change thus organizations need to be environmentally conscious in all their activities. This study gives any supply chain organization an insight on how to monitor and evaluation their supply chain activities in order to aid environmental sustainability.

An excel application has been developed using this methodology in order to make it easier for organizations to carry out their own performance appraisal. As shown in figure 7 and 8 below. 


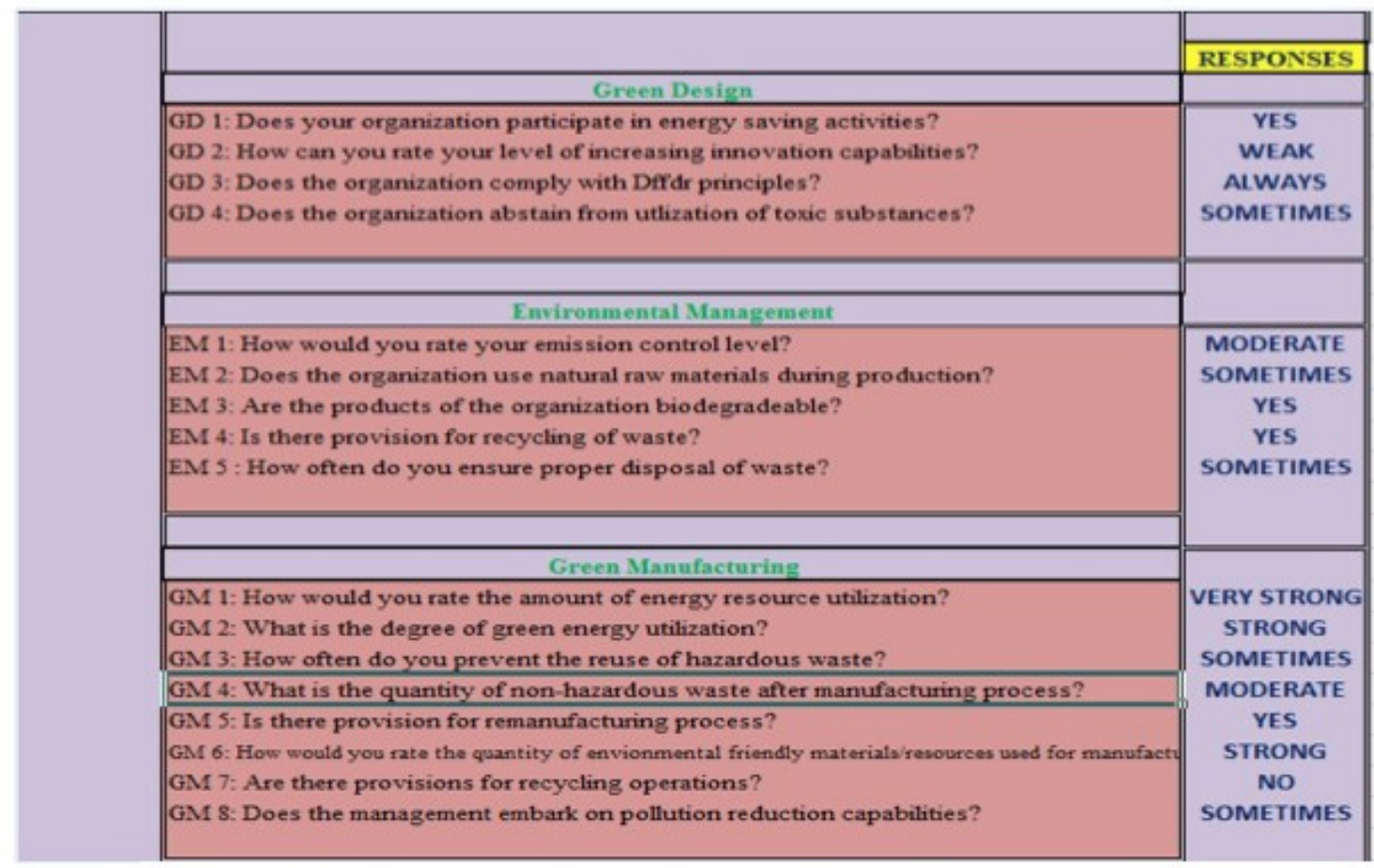

Figure 7. The input section of the performance appraisal application

\begin{tabular}{|c|c|c|c|c|c|c|c|}
\hline & & & GRFEN DESIGN & & & & \\
\hline STATE & Range & Indicator & Subcriteria & Level Descriptor & Score & Semmary & \\
\hline Excellent & $88-100$ & & GD 1: Energy Saving & 100 & 32.41 & SCORE & 71.7925 \\
\hline Satisfactory & $66-87$ & & CD $₹$ Increasing Innoration Capacity & 25 & 3.3925 & STATE & SATISFACTORY \\
\hline \begin{tabular}{|l|l} 
Acceptable \\
\end{tabular} & $46-65$ & & GD \& Complying with DFPDR principles & 100 & 17.96 & LINDICATOR & \\
\hline Alert & $33-45$ & & GD \& Abstaining from utilizing toxic substanced & 50 & 18.03 & & \\
\hline \multirow[t]{3}{*}{ Catastrophic } & 0.32 & & & Score & 71.7925 & & \\
\hline & & & & & & & \\
\hline & & & ENVIRONMENTAL MANAGEMENT & & & & \\
\hline STATE & Range & Indicator & Subcriteria & Level Dekriptor & Score & Summary & \\
\hline Excellent & $79-100$ & & EMr 1: Eminision Control & so & 12.825 & SCORE & 66.565 \\
\hline Satisfactory & $66 \cdot 78$ & & EN 2: Che of natural raw materials & 50 & 9.31 & STATE & SATISFACTORY \\
\hline Acceptable & $52-65$ & & EM 3 : Biodegradable products & 100 & 14.01 & INDICATOR & \\
\hline Alert & $31-51$ & & EMI : Feecrcling of waste & 100 & 19.12 & & \\
\hline \multirow[t]{3}{*}{ Catastrophic } & $0-30$ & & Eur 5: Proper disposal & 50 & 11.3 & & \\
\hline & & & & Score & 66.565 & & \\
\hline & & & GREFN MANUFACTLRIVG & & & & \\
\hline & & & & & & & \\
\hline STATE & Range & Indicator & Seubcriteria & Level Descriptor & Scome & Summary & \\
\hline Excellent & $83-100$ & & GM 1: Amount of energr atilization & 100 & 10.96 & SCORE & 61.945 \\
\hline Satisfactory & $69-82$ & & GM 2: Green degree of energy & 75 & 9.3675 & STATE & ACCEPTABLE \\
\hline \begin{tabular}{|l|l} 
Acceptable \\
\end{tabular} & $45-68$ & & GMI 3: Reuse times of hazardous waste & so & 7.74 & INDICATOR & \\
\hline Alert & $21-44$ & & GM 4: Quantity of hasardous waste? & so & 7.74 & & \\
\hline \multirow[t]{5}{*}{ Catastrophic } & 0.20 & & GMS 5 : Ria-massufacturing & 100 & 9.24 & & \\
\hline & & & GM 6 : Cie of eav. friendly raw materials & 75 & 9.8625 & & \\
\hline & & & GMS 7: Recyeling & o) & & & \\
\hline & & & GM 8 : Pollution Reduction capabilities & 50 & 7.035 & & \\
\hline & & & & & 61.945 & & \\
\hline
\end{tabular}

Figure 8. Application showing appraisal results based on the input/response 


\section{References}

Ali, D., Kannan, G. (2010). An analysis of the drivers affecting the implementation of green supply chain management. Resources, Conservation and Recycling, 55(6), 659-667. http://dx.doi.org/10.1016/j.resconrec.2010.12.002

Beamon, B.M. (1999). Designing the green supply chain. Logistics Information Management, $12(4), 332-342$.

Carnero, M.C. (2009). Evaluating a maintenance department in a service company. International Journal of Mathematical models and methods in applied sciences, 3(3).

Chan, R.Y.K., He, H., Chan, H.K., Wang, W.Y.C. (2012). Environmental orientation and corporate performance: The mediation mechanism of green supply chain management and moderating effect of competitive intensity. Industrial Marketing Management, 41(4), 621630. http://dx.doi.org/10.1016/j.indmarman.2012.04.009

Chiau-Ching, C., Hsu-Shih, S., Huan-Jyh, S., Kun-Shan, W. (2012). A business strategy selection of green supply chain management via an analytic network process. Computers \& Mathematics with Applications, 6(8), 2544-2557. http://dx.doi.org/10.1016/j.camwa.2012.06.013

Kuo-Jui, W., Ming-Lang, T., Truong, V. (2011). Evaluation the drivers of green supply chain management practices in uncertainty. International Conference on Asia Pacific Business Innovation \& Technology Management. Procedia - Social and Behavioral Sciences 25, 384397. http://dx.doi.org/10.1016/j.sbspro.2012.02.049

Kuo, T.-C., Liao, Y.-J., Chio, J.-X. (2004). Construction and analysis of a green supply chain management system in re-production environment. Proceedings of the 2004Annual Conference of Chinese Institute of Industrial Engineers. Tainan, Taiwan, Dec. 18 (in Chinese).

Lai, Y.-F. (2004). Green supplier evaluation in green supply chain management - examples of printed circuit board suppliers. Unpublished Master's Thesis, Department of Resource Engineering, National Cheng-Kung University, Taiwan (in Chinese).

Lin, S., Juang, Y. (2008). Selecting Green Suppliers with Analytic Hierarchy Process for Biotechnology Industry. Operations and supply chain management, 1(2, September 2008), 115-129. ISSN 1979-3561|EISSN 1979-3871.

Ming-Lang, T., Ru-Jen, L., Yuan-Hsu, L., Rong-Hui, C., Kimhua, T. (2013). Close-loop or open hierarchical structures in green supply chain management under uncertainty. Expert Systems with Applications, 41(7), 3250-3260. http://dx.doi.org/10.1016/j.eswa.2013.10.062

Odeyale, S.O., Alamu, O.J., Odeyale, E.O. (2013). Evaluation and selection of an effective green supply chain management strategy: A case study. International Journal of Research Studies in Management, 3(1), 27-39. http://dx.doi.org/10.5861/ijrsm.2013.550 
Payman, A., Cory, S. (2013). A comparative literature analysis of definitions for green and sustainable supply chain management. Journal of Cleaner Production, 52, 329-341. http://dx.doi.org/10.1016/j.jclepro.2013.02.018

Ru-Jen, L., Rong-Huei, C., Thi-Hang, N. (2011). Green supply chain management performance in automobile manufacturing industry under uncertainty. International Conference on Asia Pacific Business Innovation \& Technology Management. Procedia - Social and Behavioral Sciences, 25, 233-245.

Saaty, T.L., Vargas, L.G. (1982). The logic of priorities- applications in business, Energy, Health and Transportation. U.S.A.: Kluwer- Nijhoff Publishing.

Webb, L. (1994). Green purchasing: forging a new link in the supply chain. American Society of Agricultural Engineers, 1(6), 14-18.

Yao-Fen, W., Su-Ping, C., Yi-Ching, L., Chen-Tsang, T. (2013). Developing green management standards for restaurants: An application of green supply chain management. International Journal of Hospitality Management, 34, 263-273. http://dx.doi.org/10.1016/j.ijhm.2013.04.001

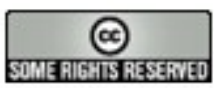

Article's contents are provided on a Attribution-Non Commercial 3.0 Creative commons license. Readers are allowed to copy, distribute and communicate article's contents, provided the author's and Journal of Industrial Engineering and Management's names are included. It must not be used for commercial purposes. To see the complete license contents, please visit http://creativecommons.org/licenses/by-nc/3.0/. 